\title{
Effect of epidermal papillomatosis on survival of the freshwater fish Rutilus rutilus
}

\author{
Raine Kortet $^{1, *}{ }^{\text {, Anssi Vainikka }}{ }^{1}$, Jouni Taskinen ${ }^{1,2}$ \\ ${ }^{1}$ Department of Biological and Environmental Science, University of Jyväskylä, PO Box 35, 40014 Jyväskylä, Finland \\ ${ }^{2}$ Institute of Applied Biotechnology, University of Kuopio, PO Box 1627, 70211 Kuopio, Finland
}

\begin{abstract}
Epidermal papillomatosis occurs in several marine and freshwater fish species. Previously, papillomatosis has been shown to induce mortality in juvenile carp. We studied the effect of epidermal papillomatosis on the survival of adult male roach Rutilus rutilus by caging naturally diseased, marked (by us) fish in the field. Within the constraints of the experimental design, there was no difference in survival between healthy, slightly diseased and heavily diseased fish. Therefore, we conclude that the possible effect of epidermal papillomatosis on the mortality of wild roach is relatively minor.
\end{abstract}

KEY WORDS: Spawning papillomatosis $\cdot$ Virulence $\cdot$ Papilloma $\cdot$ Tumour

Resale or republication not permitted without written consent of the publisher

\section{INTRODUCTION}

Epidermal papillomatosis is likely a virus-induced neoplastic skin disease, occurring in several marine and freshwater fish species (Bylund et al. 1980, Möller \& Anders 1985, Sano et al. 1991, Lee \& Whitfield 1992, Mellergaard \& Nielsen 1995, Premdas et al. 1995). However, viral agents have not been observed or defined in all cases of papillomatosis, and many different papillomata on fishes can be the result of a number of different infectious and non-infectious causes. Sano et al. (1991) studied the mortality of fish infected experimentally with cyprinid herpesvirus 1 (CHV, Herpesvirus cyprini). CHV induced papillomatosis and mortality in the fry of carp Cyprinus carpio L., but did not affect the survival of adult carp, or the fry of crucian carp Carassius carassius, grass carp Ctenopharyngodon idella or willow shiner Gnathopogon elongus caerulescens. Except for the study by Sano et al. (1991), the possible biological significance of papillomatosis, such as the effects on fish survival and reproduction, has not been experimentally studied, in spite of its wide occurrence. The clinical presentation of epidermal papillomatosis in roach includes white, smooth, loosely attached ovoid tumours on the skin and fins of fish. During severe papillomatosis, fish skin may be totally covered by a hyperplasmic epidermis (Kortet et al. 2002). Previously, the prevalence of papillomatosis has been reported to increase with fish size (Anders \& Möller 1985, Lee \& Whitfield 1992, Kortet et al. 2002), and to be higher among male fish (Kortet et al. 2002).

Roach is a common cyprinid fish which spawns in large groups in spring (Mills 1991). In a previous study, we reported that the seasonal pattern of papillomatosis of roach peaks during spawning (Kortet et al. 2002). The aim of the present study was to explore the effect of epidermal papillomatosis on the survival of roach. Because of the strong sex- and size-dependence (male and large-size based) of the disease (Kortet et al. 2002), we selected males of approximately similar sizes for the experiment. Papillomata have been suggested to erupt in fish due to physiological stress factors, such as anoxia or environmental pollutants (Mellergaard \& Nielsen 1995, Premdas et al. 1995, Kortet et al. 2002). In addition, epidermal papillomatosis has been shown to be associated with high levels of circulating sex hormones in white sucker Catostomus commersoni (Premdas et al. 2001) and roach (Kortet et al. 2003). Therefore, we started the present experiment during the period of spawning, and exposed the experimental 
groups to relatively harsh starvation and crowding stressors. The duration of the experiment, $35 \mathrm{~d}$, was chosen based on the findings of our previous study, in which a remarkable decrease in the prevalence of papillomatosis took place in the roach population over this period of time (Kortet et al. 2002).

\section{MATERIALS AND METHODS}

The study was conducted with the permission of the Central Finland regional Environmental Centre (Permission No. LS-16/00). We collected adult roach with a fyke net during the spawning period in late May 2001 from Lake Jyväsjärvi, near the city of Jyväskylä, Finland $\left(62^{\circ} 14^{\prime} \mathrm{N}, 25^{\circ} 46^{\prime} \mathrm{E}\right)$. Immediately after capture, we lightly anaesthetised the fish using $0.01 \%$ MS-222 (tricane methanesulfanate, Sigma Chemical), and measured their fork lengths. We selected male fish measuring $170 \pm 10 \mathrm{~mm}$ in length. The males were recognised by their sexual ornamentation (Taskinen \& Kortet 2002) and by the milt they released. We categorised a total of 170 male fish into 3 groups ( 0 to 2 ) according to the severity of their papilloma neoplasms: (0) fish with no visible tumours; (1) fish with fewer than 5 small $(<5 \mathrm{~mm}$ diameter) tumours or 1 medium sized (from 5 to $10 \mathrm{~mm}$ in diameter) tumour; (2) fish with at least $1 / 4$ of their skin covered by papillomas. Papillomatosis of roach in the population of the present study has previously been identified histologically (Kortet et al. 2002). We marked fish by removing the distal $2 \mathrm{~mm}$ of the ventral fin (left or right). The fish were allowed to recover and were placed in plastic cylinder cages (height $700 \mathrm{~mm}$, diameter $500 \mathrm{~mm}$, mesh size $10 \mathrm{~mm}$ ). In 9 cages, we placed 5 non-diseased (Group 0 ) and 5 slightly diseased (Group 1) fish. In 8 cages, we placed 5 non-diseased (Group 0) and 5 heavily diseased (Group 2 ) fish. The cages were placed on the lake bottom in shallow water $(0.7 \mathrm{~m}$ depth), thus enabling the fish to obtain their normal food. We gave the fish no extra food in order to induce relatively harsh starvation stress to elucidate the reasons for possible disease-induced mortality. Two of the cages were lost during the experiment, leaving only 8 cages with Group 0 plus Group 1 fish and 7 cages with Group 0 plus Group 2 fish for the analyses. Thus, the final number of fish in the study was 150. The survival of the fish was observed daily for $35 \mathrm{~d}$, with dead specimens being removed daily.

We used Kaplan-Meier survival analysis to study the effect of epidermal papillomatosis on the survival of fish. Healthy fish versus lightly diseased fish and healthy fish versus heavily diseased fish were analysed separately, using papillomatosis as a factor and with cages pooled. Although differences in the survival of fish between cages were expected, pooling was possible since we had equal numbers of healthy and diseased fish in each cage. The differences between cages were also analysed separately, using cage as a factor and with papillomatosis groups pooled. Statistical analyses were performed using the SPSS statistical package.

\section{RESULTS}

Papillomatosis did not increase fish mortality. Survival of non-diseased fish (mean \pm SE: survival time $28.3 \pm 1.3$ d) did not differ from that of slightly diseased fish (29.3 \pm $1.3 \mathrm{~d}$ ), as indicated by the results of the survival analysis (log rank $=0.69, \mathrm{df}=1, \mathrm{p}=0.407)$. The mean survival time of heavily diseased fish $(30.8 \pm 1.2 \mathrm{~d})$ differ from that of non-diseased fish $(28.6 \pm 1.3 \mathrm{~d})$ did not $(\log$ rank $=$ $0.32, \mathrm{df}=1, \mathrm{p}=0.571)$. The mortality of fish during the 35 d experiment was 48 (36/75), 40 (16/40) and $43 \%$ (15/35) among healthy, slightly diseased and heavily diseased fish, respectively. The total mortality over all experimental groups was $45 \%(67 / 150)$.

Differences in survival between the cages were statistically significant. Among the cages where healthy and slightly diseased fish were placed together, the mean survival ranged from 24.2 to $35.0 \mathrm{~d}$ (log rank = 21.9 , $\mathrm{df}=7, \mathrm{p}=0.003$ ). Similarly, among the cages containing healthy and heavily diseased fish, the mean survival ranged from 23.1 to $33.9 \mathrm{~d}$ (log rank $=21.54$, $\mathrm{df}=6, \mathrm{p}=0.002$ ). The spatial pattern of fish survival among the cages was random.

\section{DISCUSSION}

The present study is the first to assess the effect of papillomatosis on the survival of wild fish under seminatural conditions. Papilloma disease did not induce mortality in roach in the present experiment, although in some heavily diseased individuals papillomas covered most of the skin. The fish were subjected to relatively harsh starvation and crowding stressors, as indicated by the high total mortality of fish during the experiment. Therefore, our results should be interpreted within the constraints of the experimental design, and may not be directly applied to natural conditions. Sano et al. (1991) found that mortality induced by papillomatosis (CHV) occurred only in fish fry, and was species specific. Therefore, the results of the current experiment on adult roach do not exclude the possibility that juvenile roach could be susceptible to papillomatosis-induced mortality. Moreover, we cannot rule out the possibility that excessive stocking of fish in cages in our experiment could have led to increased mortality for all groups, regardless of disease condition. 
It may be concluded that the decrease in prevalence of papillomatosis from peak occurrence at the time of spawning (late May and early June) to July, found by Kortet et al. (2002) in the population of the present study, and the concurrent decrease in the intensity of the disease, may be produced by a regression of papilloma tumours rather than by disease-induced mortality of the fish. However, to adequately reach this conclusion would require mark-recapture studies and grading of tumour severity to document the actual regression.

Papillomatosis did not increase the mortality of caged roach, but the results of the present study do not rule out the possibility that papillomatosis could increase fish mortality by increasing the risk of predation by fish or birds (by the whitening of skin and by impairing the movements of the most diseased fish). Therefore, the possible effect of papillomatosis on predation-induced mortality of fish should be investigated in the future.

Acknowledgements. We are grateful to J. Pönkä, J. Myntti, V. Sakomaa and L. Manninen for assistance in the field. R. Jones gave valuable comments on the manuscript and provided assistance with the English language. We also thank the Emil Aaltonen Foundation and the Maj \& Tor Nessling Foundation for grants to R.K. and J.T., respectively.

\section{LITERATURE CITED}

Anders K, Möller H (1985) Spawning papillomatosis of smelt, Osmerus eperlanus L., from the Elbe estuary. J Fish Dis 8: 233-235

Editorial responsibility: Jo-Ann Leong,

Kaneohe, Hawaii, USA
Bylund G, Valtonen ET, Niemelä E (1980) Observations on epidermal papillomata in wild and cultured Atlantic salmon Salmo salar L. in Finland. J Fish Dis 3:525-528

Kortet R, Vainikka A, Taskinen J (2002) Epidermic epizootic cutaneous papillomatosis in roach (Rutilus rutilus): sex and size dependence, seasonal occurrence and between population differences. Dis Aquat Org 52(3):185-190

Kortet R, Vainikka A, Rantala MJ, Jokinen I, Taskinen J (2003) Sexual ornamentation, androgens and papillomatosis in male roach (Rutilus rutilus). Evol Ecol Res 5: 411-419

Lee S, Whitfield PJ (1992) Virus-associated spawning papillomatosis in smelt, Osmerus eperlanus L., in the River Thames. J Fish Biol 40:503-510

Mellergaard S, Nielsen E (1995) Impact of oxygen deficiency on the disease status of common dab Limanda limanda. Dis Aquat Org 22:101-114

Mills CA (1991) Reproduction and life history. In: Winfield IJ, Nelson S (eds) Cyprinid fishes: systematics, biology and exploitation. Chapman \& Hall, London, p 483-508

Möller H, Anders K (1986) Diseases and parasites of marine fishes, tumors and tumor-like lesions. Möller, Kiel, p 39-59

Premdas PD, Metcalfe TL, Bailey ME, Metcalfe CD (1995) The prevalence and histological appearance of lip papillomas in white suckers (I) from two sites in central Ontario, Canada. J Gt Lakes Res 21:207-219

Premdas PD, Metcalfe CD, Brown S (2001) The effects of $17 \beta$ oestradiol, testosterone and tamoxifen on the development of papillomata in Catostomus commersoni. J Fish Biol 59:1056-1069

Sano T, Morita N, Shima N, Akimoto M (1991) Herpesvirus cyprini: lethality and oncogenity. J Fish Dis 14:533-543

Taskinen J, Kortet R (2002) Dead and alive parasites: sexual ornaments signal parasite resistance in the male fish Rutilus rutilus. Evol Ecol Res 4:919-929

Submitted: April 20, 2003; Accepted: August 1, 2003

Proofs received from author(s): September 4, 2003 